\title{
METODOLOGIAS ATIVAS NOS CURSOS DE DIREITO: NOTAS ACERCA DA UTILIZAÇÃO DO MÉTODO DO CASO
}

\author{
Manoel Monteiro Neto ${ }^{1}$ \\ Horácio Wanderlei Rodrigues ${ }^{2}$
}

\begin{abstract}
Resumo: O objeto do trabalho é tratar das possibilidades de aplicação do método do caso no ensino do Direito, de maneira compatível com a dogmática jurídica, por meio de abordagem qualitativa e procedimento bibliográfico. A pesquisa busca apresentar uma alternativa viável, já testada, como forma de resolver o problema identificado, qual seja o distanciamento entre a realidade e a educação jurídica teórico-conceitual atualmente praticada. Estabelecer metodologias ativas, com a participação dos alunos no processo de aprendizagem, é o caminho já identificado no campo da pedagogia. E na área do Direito, o método do caso é uma alternativa, dessa espécie, já devidamente corroborada. A aplicação desse método deve trazer significativos resultados na aprendizagem e na compreensão do Direito, se adequadamente utilizada.
\end{abstract}

Palavras-chave: Educação jurídica. Método do caso. Metodologias ativas.

\section{ACTIVE METHODOLOGIES IN LAW SCHOOLS: NOTES ABOUT THE USE OF THE CASE METHOD}

\begin{abstract}
The object of the paper is to deal with the possibilities of applying the case method in the teaching of Law, in a manner compatible with legal dogmatics, through a qualitative approach and bibliographic procedure. The research seeks to present a viable alternative, already tested, as a way to solve the identified problem, which is the distance between reality and the theoretical-conceptual legal education currently practiced. Establishing active methodologies, with the participation of students in the learning process is the path already identified in the field of pedagogy. And in the area of Law, the case method is an alternative of that kind, already duly corroborated. The application of this method should bring significant results in learning and understanding the Law, if properly used.
\end{abstract}

Keywords: Legal education. Case method. Active Methodologies.

\section{INTRODUÇÃO}

\footnotetext{
${ }^{1}$ Mestrando em Direito no PPGD/UNIVEM. Especialista em Direito Empresarial pela Faculdade Legale.

2 Professor Visitante do PPGD/FURG e Professor Convidado do PPGD/UNICURITIBA. Professor Titular (aposentado) do DIR/UFSC. Membro do Instituto Iberomericano de Derecho Procesal. Sócio fundador do CONPEDI e da ABEDi. Bolsista de Produtividade em Pesquisa do CNPq. Doutor e Mestre em Direito pela UFSC. Estágios de Pós-Doutorado em Filosofia/UNISINOS e em Educação/UFRGS.
} 
A denominada crise da educação jurídica guarda relações estritas com o excessivo dogmatismo presente nas faculdades, produtor de um distanciamento entre os aspectos teóricos do fenômeno jurídico e suas aplicações no mundo fenomênico. Nesse contexto, até mesmo os exemplos constantes dos cursos e manuais demonstram excessiva abstração.

Nesse sentido, o objetivo do presente trabalho foi estudar as possibilidades de aplicação do chamado método do caso ao ensino do Direito, de forma compatível com o tratamento da dogmática jurídica, em uma abordagem qualitativa, utilizando-se como método primário, o dedutivo e, a título de procedimento, o bibliográfico.

O artigo trata, inicialmente, da necessidade de, na educação jurídica, se relacionar os aspectos teóricos do Direito à realidade perante a qual serão aplicados, assim como algumas possibilidades de mudança do atual quadro didático-pedagógico, especificamente por intermédio da aplicação de metodologias ativas.

A seguir são trabalhados alguns conceitos basilares do denominado método do caso, assim como suas diferenças conceituais quanto ao estudo de caso e à análise de julgados. Ao final, são estudadas algumas vantagens e advertências quanto à utilização do método do caso na educação jurídica.

Justifica-se, a pesquisa que deu origem ao presente trabalho, pela necessidade de se tentar reverter o quadro de distanciamento da realidade no qual se encontra a educação jurídica, excessivamente centrado na dogmática e separado da prática, assim como de se estabelecer métodos mais ativos, voltados à participação dos alunos no próprio processo de aprendizagem.

\section{O DOGMATISMO NA EDUCAÇÃO JURÍDICA}

Neste tópico será tratado o grau de necessidade da presença da dogmática na educação jurídica, bem como a indispensabilidade de se relacionar os aspectos teóricos do Direito à realidade, e possibilidade de mudança pela aplicação de aplicação de métodos casuísticos. 


\subsection{Dogmática jurídica: entre necessidade e excesso}

A dogmática, especialmente relacionada à letra da lei e à interpretação do ordenamento pelos estudiosos do Direito, tem se demonstrado o aspecto central da educação jurídica. Trata-se de um aspecto indispensável, que não pode ser eliminado dos currículos das faculdades, por mais ampla que seja a liberdade de ensinar.

Até porque a liberdade de ensinar é liberdade limitada, “[...] pois divide espaço com a liberdade de aprender dos alunos e com as garantias mais amplas de pluralismo de ideias e de abordagens pedagógicas, integrando todas o Direito maior, que é o Direito à educação", e contextual, por se manifestar no âmbito de um conjunto de normas, diretrizes e planejamentos. (RODRIGUES, 2012, p. 370.).

Desse modo, a atividade docente, inclusive no ensino superior, em que pese a liberdade de ensinar constitucionalmente consagrada, é parcialmente regulada, de forma que precisa ser exercida em obediência à legislação aplicável, às diretrizes curriculares nacionais e a outras normas regulatórias.

Nesse sentido, o estudo dogmático do Direito decorre da necessidade de determinação do sentido das normas para sua posterior aplicação, de maneira que necessita “[...] seguir a sua evolução doutrinária e jurisprudencial para chegar à sua significação presente". Além disso, é preciso que acompanhe a evolução jurisprudencial. (AZEVEDO, 2006, p. 223-224.).

Trata-se do caminho percorrido pela "[...] experiência histórica por que passam as normas”. Não é, contudo, um percurso caracterizado pela neutralidade ou pela lógica formal. Além disso, não é capaz de "[...] afastar as opções, vale dizer, as valorações perceptíveis em seu curso, através do tempo". Assim, o estudo do Direito não se resume ao aprendizado acrítico do direito positivo. (AZEVEDO, 2006, p. 224.).

Caso assim o fosse, o mundo dos juristas se afastaria do mundo real, "[...] fazendo emergir o ceticismo do convívio de duas verdades a do povo e a dos juristas. Assim, a metodologia deve ser revisada para que o aluno possa contextualizar a experiência jurídica, pois o trabalho da dogmática jurídica é lógico-descritivo. (AZEVEDO, 2006, p. 224-225.). 
Ocorre que não há razão para se estudar as leis e conceitos jurídicos de acordo com uma perspectiva meramente lógico-textual e indiferente à sua significação contextual: “[...] o autêntico estudo do Direito é criativo e sensível ao quadro histórico a que se destina. Para isto, trata de unir as diferentes perspectivas do Direito, ao invés de cindi-las, em nome de uma pseudociência do Direito". (AZEVEDO, 2006, p. 225.).

O ensino da dogmática jurídica é indispensável como instrumento de compreensão do fenômeno jurídico em toda a sua complexidade. Mas o processo de ensino-aprendizagem do direito positivo exige mais do que a sua descrição teórico-conceitual. A teoria, como descrição e interpretação das normas, não pode ser o único aspecto a ser trabalhado nos cursos de Direito.

\subsection{A necessidade de materialização da teoria}

Em decorrência da necessidade de se incorporar a dogmática ao ensino do Direito, o fenômeno jurídico acaba por ser tratado como uma abstração de um mundo ideal que, por sua vez, difere daquilo que se observa, diuturnamente, no mundo fenomênico. Até mesmo os exemplos utilizados são, muitas vezes, distantes da realidade.

Nas aulas de Direito, o concreto aparece para comprovar ou ilustrar, ou surge por meio de exercícios de aplicação voltados a ensinar o aluno a usar as fórmulas abstratas em situações reais de forma mais segura, a exemplo do que ocorre nas aulas de prática jurídica. $\mathrm{Na}$ tradição didática jurídica, porém, o contato direto com o mundo real não é valorizado como base de aprendizado. (SUNDFELD; PALMA, 2012, p. 169.).

Esse distanciamento, entre teoria e realidade, é prejudicial não apenas em relação ao entendimento acerca da escrita jurídica, mas, também, para a compreensão acerca da capacidade do Direito de conformar a realidade e corrigir injustiças sociais e econômicas. $\mathrm{O}$ entendimento da aplicação dos institutos jurídicos não é uma questão meramente tecnicista.

A transformação da cultura jurídica se inicia com a mudança no ensino dos institutos. Essa abordagem demanda "[...] uma sistemática que não se limite à exposição de conteúdo por parte do professor", de modo que a reprodução de casos concretos como ferramenta de 
ensino é essencial para a compreensão da necessidade de se apreender as circunstâncias de fato, para além da teoria. (SAID FILHO; ACIOLY FILHO, 2020, p. 118.).

A dogmática jurídica, contudo, “[...] insiste em trabalhar com perspectivas simplificadoras na criação das normas" (SAID FILHO; ACIOLY FILHO, 2020, p. 119.). Dessa forma, o estudo do Direito não prepara para responder às novas formas de conflitos, oriundos das emergentes contradições econômicas, políticas, sociais, culturais e axiológicas, típicas de uma sociedade plural e democrática.

Além disso, não é “[...] capaz de lidar com a emergência de comportamentos crescentemente desafiadores aos diferentes códigos e leis em vigor" (SAID FILHO; ACIOLY FILHO, 2020, p. 119-120.). Ocorre que o modelo que predomina no formato educacional jurídico-acadêmico ainda é de influenciado pelo racionalismo idealista, insensível às circunstâncias que circundam o Direito, ou resistente à sua assimilação.

A modificação desse quadro limitativo da compreensão do Direito passa, necessariamente, pela consolidação de metodologias que permitam o contato entre a dogmática aprendida e a prática vivida, todavia, obedecendo à regulamentação determinada pelos diplomas normativos incidentes sobre a educação jurídica.

\subsection{Os métodos casuísticos no ensino do Direito}

Apesar de a capacidade de abstração ser uma das competências a serem buscadas pelo ensino do Direito, o dogmatismo exacerbado acaba por ocasionar o distanciamento entre o raciocínio jurídico e a realidade perante a qual deve ser aplicado, acabando por se converter, perigosamente, em uma atividade meramente conceitual.

Os métodos casuísticos são instrumentos metodológicos voltados a auxiliar no aprendizado e exercitar a capacidade de interpretar fenômenos, permitindo que o aluno demonstre, na prática, o conhecimento adquirido nas aulas, bem como que o professor acompanhe o aprendizado dos discentes e a efetividade da metodologia. (SAID FILHO; ACIOLY FILHO, 2020, p. 123.). 
Alunos e professores avaliam argumentos contrários e favoráveis às soluções apresentadas ao problema exposto, induzindo a atividade de pesquisa, não mais limitada à letra da lei, expandindo-a para a decisões judiciais e aplicação concreta das teorias jurídicas estudadas. Também auxilia no desenvolvimento da crítica, à construção de argumentos e respostas e à reestruturação do pensamento. (SAID FILHO; ACIOLY FILHO, 2020, p. 124.).

O professor tem o papel fundamental de conduzir os debates e a construção de soluções, pois a tendência é que diferentes alunos enxerguem o problema e a solução de maneira distinta, ou parcialmente divergente. Nessa pluralidade, o professor deve conduzir a exposição das ideias relacionadas à própria disciplina e a outras, para promover a comunicação entre as diversas áreas do Direito e a interdisciplinaridade. (SAID FILHO; ACIOLY FILHO, 2020, p. 124.).

As ideias e argumentos não ficam, assim, soltos e desconexos do problema e de seu contexto, possibilitando que professor e aluno sejam protagonistas no processo de produção e reprodução do conhecimento, preparando os futuros profissionais para estarem aptos para os novos problemas e campos de trabalho que emergem com a evolução regular da sociedade. (SAID FILHO; ACIOLY FILHO, 2020, p. 124-130).

Nesse contexto é que se destacam as denominadas metodologias ativas, que, ao contrário das estratégias centradas no docente, não se baseiam na passividade dos alunos, demandando sua integração ampla e direta em seu próprio processo de aprendizagem. Dentre elas é que se encontram as ferramentas casuísticas, inclusive, o método do caso.

As metodologias ativas são ferramentas que podem ser utilizadas isoladamente ou de forma complementar às demais. Elas visam proporcionar uma melhor compreensão dos conteúdos a partir do agir do próprio aluno e permitem, em especial, o desenvolvimento das competências profissionais desejadas. O método do caso é uma dessas ferramentas, situadas no âmbito das abordagens pedagógicas centradas na aprendizagem e não apenas no ensino. (RODRIGUES; BORGES, 2016, p. 1366.).

As teorias, classificações, institutos básicos, conceitos e categorias podem ser compreendidos pelo aluno por meio de casos. Apesar disso, em determinadas ocasiões, sendo imprescindível uma introdução teórica ou conceitual sobre a matéria, ela poderá ser fornecida 
ao estudante com aulas expositivas ou material para leitura individual. (RODRIGUES; BORGES, 2016, p. 1370.).

Isso ocorre porque, em algumas situações pode ser necessário o esclarecimento de alguns termos técnicos, classificações ou teorias ainda desconhecidos. Contudo, isso não impede a utilização do método do caso e nem que o mesmo alcance o objetivo de fazer o aluno aprender o conteúdo. Além disso, os casos são campo fértil para a compreensão do comportamento dos alunos. (RODRIGUES; BORGES, 2016, p. 1370-1371.).

Dessa forma, a utilização do método do caso colabora tanto para o aprendizado dos conceitos indispensáveis à compreensão da dogmática jurídica quanto para sua aproximação com a realidade na qual os referidos institutos devem ser aplicados, além de ser capaz de despertar a consciência crítica nos estudantes.

\section{O MÉTODO DO CASO}

Neste tópico serão tratados alguns conceitos basilares do denominado método do caso, assim como suas diferenças conceituais em relação ao estudo de caso e à análise de julgados. Ao final serão trazidas algumas das vantagens e cuidados quando de sua utilização na educação jurídica.

\subsection{Origem}

Convém advertir, de início, que o método do caso não faz parte da tradição da educação jurídica brasileira. Nesse contexto o docente é, regra geral, um mero transmissor de conhecimentos conceituais abstratos. Seu criador foi Christopher Collumbus Langdell, um jurista e professor de Harvard. (MENEZES, 2009, p. 137.).

Langdell, quando assumiu a direção da Escola de Direito de Harvard no final do século XIX, promoveu uma verdadeira revolução quanto ao estudo prático da lei: “[...] era o estudo da lei viva. A partir da análise dos arrazoados dos juízes, os alunos iam chegando às 
próprias conclusões sobre a legislação. Não se debruçavam apenas nos compêndios como era o caso do estudo na Alemanha". (MENEZES, 2009, p. 137-138.).

Isso porque o referido método partiu de um raciocínio lógico, todavia, “controversamente inovador", pois advogados e juízes já se utilizavam das decisões e opiniões judiciárias para arrazoarem. O método guarda relações aparentes com as atuais propostas construtivistas. (MENEZES, 2009, p. 138-140).

Originalmente o método do caso não utilizava fatos fictícios, partindo de situações reais, inclusive precedentes judiciais. Esse uso do Direito vivo como ferramenta pedagógica ainda não é prática comum no Brasil, apesar de possibilitar ao aluno a construção do próprio conhecimento, a concluir por si mesmo sobre a teorias, a partir da análise de casos concretos. A tradição brasileira é inversa, da lei e da teoria para o caso - ensino dedutivo. (MENEZES, 2009, p. 140.).

O método do caso pode, nesse contexto, auxiliar na construção de uma nova mentalidade docente relativamente ao processo de ensino aprendizagem, de forma a melhorar a formação dos futuros profissionais (MENEZES, 2009, p. 140-141.), especialmente em decorrência de viabilizar o desenvolvimento de competências.

O método do caso se relaciona à reconstituição de entendimentos pelo estudo seriado, pois o "[...] domínio efetivo da doutrina está no estudo dos casos em que esteja ela incorporada", demandando que o estudante observe o Direito como constituído por princípios a serem encontrado nos julgados. (CONANT, 1968, p. 77.).

O referido método é, reconhecidamente, uma criação dos juristas americanos que lecionavam na Faculdade de Direito de Harvard tendo, a partir dela, se expandido para as outras instituições de educação jurídica americanas. Trata-se de uma aplicação, no ensino do Direito, dos princípios demandados pela natureza mesma da common law. (CONANT, 1968, p. 79.).

$\mathrm{Na}$ análise crítica do caso legal utiliza-se o método indutivo, que seria o "[...] único completamente adaptado à natureza do Direito anglo-americano" que, por sua vez, não opera por meio de "[...] conclusões derivadas dedutivamente de verdades pré-estabelecidas de validade universal e inflexível". O método indutivo, nesse sentido, retira dos particulares as suas generalizações. (CONANT, 1968, p. 79-84.). 
As regras e princípios do case law não podem ser tratadas como como verdades finais, mas, sim, “[...] como hipóteses de trabalho continuamente testadas e retestadas nos grandes laboratórios do Direito, que são as Cortes de Justiça". Por isso é que "[...] o método de caso usado na Escola (Harvard Business) baseia-se no princípio de que se aprende fazendo". (CONANT, 1968, p. 84-89.).

Volta-se, nesse sentido, a desenvolver no estudante a capacidade de tomar decisões e criar condições adequadas para a ação, colocando-o, para tanto, em situações nas quais deve avaliar fatos, pesar opiniões e agir de forma responsável, enfatizando a tomada de decisão em situações realísticas e concretas. (CONANT, 1968, p. 89.).

São utilizados estudos econômicos e o condicionamento à adaptação a problemas de administração de conhecimentos, competências e "[...] métodos de análise derivados de todas as ciências do comportamento" (CONANT, 1968, p. 89-90.).

O método relaciona-se, originalmente, como já referido, ao ensino do Direito nos sistemas de tradição jurídica da common law. Apesar de o Brasil ser um país de tradição jurídica romano-germânica, é possível, entretanto, adaptar a referida metodologia à civil law nacional, especialmente após ter o Código de Processo Civil de 2015 introduzido no sistema jurídico brasileiro os precedentes.

\subsection{Caracterização}

O método do caso permite trabalhar com um caso já solucionado, assim como estudar possíveis soluções e resultados hipotéticos. No primeiro caso, o aluno deve analisar a situação no todo e identificar pontos positivos e negativos, assim como propor soluções alternativas e indicar novos problemas, “[...] gerando, por consequência, novos casos problema para análise”. (RODRIGUES; BORGES, 2016, p. 1374.).

No segundo caso, é necessário identificar os problemas e apresentar soluções, de forma que o aluno "[...] deverá identificar os potenciais problemas que podem surgir, analisar e propor eventuais soluções para cada um dos problemas, bem como prever os resultados possíveis de cada uma destas soluções”. (RODRIGUES; BORGES, 2016, p. 1374-1375.). 
Como terceira possibilidade, pode-se apresentar a situação os problemas já identificados, narrando a situação fática e o problema correlato. O aluno, aqui, proporá “[...] soluções viáveis de resolução do problema, experimentando-as e, por conseguinte, identificando os resultados possíveis de cada uma dessas soluções". (RODRIGUES; BORGES, 2016, p. 1374-1375.).

Não bastasse, poderia apresentar uma alternativa ao caso, ao problema e à solução, “[...] sem indicar os resultados ou consequências decorrentes da decisão tomada", após analisar as vantagens e desvantagens da solução proposta e identificar seus eventuais resultados, positivos e negativos (RODRIGUES; BORGES, 2016, p. 1375.), demonstrandose, assim, a versatilidade dessa ferramenta.

Além disso, a participação do aluno é essencial na aplicação do referido método, já que necessita compreender tanto os institutos e conceitos dogmáticos como sua aplicação em relação a uma situação específica, seja ela passada ou presente, verifica ou fictícia, evidenciando-se, portanto, suas vantagens em relação à análise de julgados.

A aplicação do chamado método do caso ao ensino do Direito se dirige a estabelecer o contato mais direto entre a dogmática jurídica e a realidade em relação à qual deverá ser aplicada. E não deve ser confundida com outros dois instrumentos metodológicos que também tem esse mesmo objetivo, pelo menos em parte: o estudo de caso e a análise de julgados.

Apesar da similaridade entre as duas nomenclaturas, é necessário diferenciar o método do caso do estudo de caso. O primeiro é uma ferramenta de ensino, o segundo uma estratégia de pesquisa usualmente utilizado nas ciências sociais, a exemplo da administração, da economia, da sociologia, da antropologia e da ciência política e, em menor escala, também na pesquisa jurídica. ${ }^{3}$

Em relação à análise de julgados, essa ferramenta busca a visualização de diferentes formas de fundamentação de decisões e de estilos argumentativos, sendo de natureza mais comparativa, sendo que a variação de percepções sobre o mesmo objeto movimenta o

\footnotetext{
3 No Direito brasileiro, entretanto, é pouco utilizado, tendo em vista a ênfase documental da pesquisa, que lhe atribui natureza empírica. A pesquisa jurídica é tradicionalmente teórica, de cunho bibliográfico enfaticamente livresca.
} 
processo de aprendizado. Já o método do caso objetiva a compreensão de uma situação específica e não sua análise comparativa.

\subsection{Aspectos práticos na utilização do método do caso}

Uma das estratégias que pode ser utilizada para impedir a formação do hiato epistêmico entre a dogmática e a realidade e entre a técnica e sua efetiva aplicação no mundo fenomênico é o ensino a partir de situações reais ou hipotéticas, presentes ou passadas, julgadas ou em processamento. O método do caso situa-se entre essas estratégias.

Atualmente, o conhecimento sobre o Direito que se leciona nas faculdades é identificado "[...] como um tipo de produção técnica, destinada apenas a atender às necessidades profissionais (o juiz, o advogado, o promotor) no desempenho imediato de suas funções", fazendo com que o jurista teórico seja "[...] conduzido a esse tipo de especialização fechada e formalista". (FERRAZ JÚNIOR, 2019, p. 49.).

Ocorre que o objeto do conhecimento jurídico-dogmático é, justamente, uma dupla abstração, relacionada às "[...] regras sobre as regras de interpretação das normas", fazendo com que o estudioso arrisque se distanciar progressivamente da realidade social (FERRAZ JÚNIOR, 2019, p. 49-50), situação que cabe especialmente ao docente prevenir e remediar.

Assim, a utilização do método do caso pode se relacionar, de maneira específica, à segunda parte do processo de abstração, qual seja, a interpretação das normas jurídicas, entretanto, voltada à sua aplicação a uma situação concreta. Além disso, é capaz de fazer surgir ou aprimorar as competências necessárias ao futuro operador do Direito.

Os casos devem ser formulados de acordo com os objetivos de aprendizagem, todavia, conforme uma série de fatores, como o estágio do curso, o nível de maturidade e o conhecimento do ordenamento jurídico do aluno. Além disso, pode ser necessário disponibilizar material de apoio ao aluno ou até mesmo documentos relacionados ao caso. (RODRIGUES; BORGES, 2016, p. 1372.).

Na redação de um caso, é necessário “[...] selecionar aspectos de uma situação problemática e estruturar o seu texto para contemplar certos objetivos educacionais, sem, no 
entanto, revelar no corpo do caso quais são estes objetivos. Os objetivos educacionais são declarados nas notas de ensino dirigidas ao professor". (RODRIGUES; BORGES, 2016, p. 1376.).

Além disso, o professor deve "[...] desaprender o relato argumentativo próprio da redação científica. Assemelha-se ao jornalismo factual, sendo o texto recheado de fatos e depoimentos, apresentados em ordem cronológica, com o objetivo de proporcionar uma discussão bem informada do caso em sala de aula". (RODRIGUES; BORGES, 2016, p. 1376.).

No mesmo sentido, deve abrir mão da retórica e da ideologia, “[...] pois o propósito não é persuadir o leitor, mas possibilitar o aparecimento de diversas interpretações que emerge da discussão do caso", bem como deve "[...] atrair o leitor e animar a discussão do caso: no caso ideal, o relato é vívido, revela conflitos e até contém um pouco de mistério". (RODRIGUES; BORGES, 2016, p. 1376.).

É possível apresentar casos escritos, em texto ou documentalmente, assim como "[...] por meio de filmes, vídeos ou obras literárias", reais ou ficcionais, desde que "[...] consigam transmitir com clareza o caso ao aluno". No caso do texto destinado aos alunos, entretanto, é preciso redigir um outro, destinado aos professores, denominado notas de ensino (RODRIGUES; BORGES, 2016, p. 1382.), que deve conter:

[...] um resumo do caso; descrições e características dos principais atores do caso; enquadramento no tempo e no espaço do caso; os conteúdos que devem ser abordados no caso; a justificativa e a pertinência de sua utilização em determinadas disciplinas; os objetivos pedagógicos da aplicação do caso, com a descrição dos conteúdos, competências e habilidades; sugestões do método de aplicação e avaliação do caso; e referências bibliográficas pertinentes ao tema do caso. (RODRIGUES; BORGES, 2016, p. 1382.).

Além disso, as notas são destinadas a “[...] compor o acervo de casotecas, nas quais os casos ficam à disposição de um grupo de professores (ou mesmo da comunidade em geral, em especial quando as casotecas são virtuais)". Em que pese a existência desses requisitos, “[...] não existe uma regra ou fórmula preestabelecida para a aplicação do Método do Caso". (RODRIGUES; BORGES, 2016, p. 1384.).

Apesar disso, há algumas etapas a serem cumpridas. Inicialmente, é preciso escolher um caso real, formular um caso fictício ou adaptar e complementar caso real. Em segundo 
lugar, é necessário explicar a atividade e os objetivos de aprendizagem e preparar os alunos para o estudo. Após, “[...] o caso será apresentado aos alunos”, por escrito e explicado em sala de aula. (RODRIGUES; BORGES, 2016, p. 1384.).

Em quarto lugar, desenvolve-se o estudo, individualmente ou em grupos, em horário de aula ou não. No caso da formação de grupos, “[...] é interessante a designação de um coordenador”. Finalmente, serão debatidas as soluções propostas e os conteúdos aprendidos, bem como serão demonstradas as habilidades e competências desenvolvidas. (RODRIGUES; BORGES, 2016, p. 1384-1385.).

Demonstra-se, assim, não se tratar de uma ferramenta de aplicação simples, em decorrência do fato de demandar sério e dedicado preparo de parte do docente que se dispõe a utilizá-la. Além de se preocupar com o procedimento preliminar, o professor deve ter em mente as técnicas necessárias para tanto, assim como deve avaliar os resultados do exercício.

\subsection{Vantagens na utilização do método do caso}

Além das diferenças em relação ao ensino meramente dogmático-conceitual do Direito, o método do caso apresenta características vantajosas, no âmbito das metodologias ativas, especialmente no que concerne à aproximação entre os aspectos teóricos do fenômeno jurídico e sua aplicação na realidade.

O esforço de se trabalhar com casos concretos permite que, a partir de problemas reais e textos disciplinares, surjam “[...] as condições e o ambiente de inquietação intelectual necessário para induzir o aluno a tornar-se autor de suas convicções: sutilmente, sai de cena o professor e entra o aluno como o ator principal de seu próprio processo de aprendizado". (SANTI, 2009, p. 146.).

Por intermédio do trabalho pedagógico que utiliza situações práticas, possibilita-se que, mesmo no interior de uma sala de aula, os alunos alcancem maior capacidade de abstração, referente, especificamente, à aplicação dos institutos dogmáticos a uma situação realística. Um dos instrumentais aplicáveis para tanto é, justamente, o método do caso. 
Por seu intermédio faz-se possível até mesmo identificar os perfis de ação dos alunos, separando os líderes, aqueles que se colocam a organizar e aqueles que se comportam de maneira ativa ou reativa, bem como os estudantes que se prontificam a argumentar, explanar e convencer. Além disso, possibilita-se despertar o conhecimento interdisciplinar. (RODRIGUES; BORGES, 2016, p. 1370-1371.).

No mesmo sentido, ao permitir e incentivar o debate de interpretações e ideias, viabiliza uma aproximação dos próprios alunos entre si e, consequentemente, o intercâmbio de conhecimentos e questionamentos, produzindo sua evolução conceitual, prática e crítica, bem como desenvolvendo sua adaptabilidade às situações supervenientes.

Referida abordagem tem repercutido intensamente na academia e se configura, atualmente, em prática cada vez mais rotineira nos estudos jurídicos pátrios, tendo demonstrado capacidade para trabalhar uma diversidade de competências necessárias ao profissional do Direito (PLASTINA JÚNIOR; LEAL, 2018, p. 16.). Dentre elas estão:

[...] a interpretação da situação; identificação, diagnóstico e delimitação do problema proposto; separação, dentro do problema, daquelas questões ou informações que são mais relevantes além de tecer e sistematizar possíveis soluções para o caso. Acrescenta-se, ainda, no plano das habilidades - mais prático, de execução - o desenvolvimento do aluno para que o mesmo redija, aplique e teste as soluções levantadas para o problema; verificando quais as consequências, bem como eventuais soluções alternativas para determinado caso. (PLASTINA JÚNIOR; LEAL, 2018, p. 16.).

Dessa forma, apesar de ainda não ser uma ferramenta didática plenamente difundida e utilizada no meio jurídico acadêmico, referido método parece ser capaz de ampliar as possibilidades de compreensão de conceitos e de aquisição de competências e habilidades indispensáveis a um bom profissional do Direito. 


\section{CONSIDERAÇÕES FINAIS}

A dogmática jurídica é aspecto indispensável do estudo do Direito, de modo que não pode ser eliminado dos currículos das faculdades, mesmo considerando a liberdade de ensinar, até porque a atividade docente é deve ser exercida em obediência à legislação aplicável, às diretrizes curriculares do curso e ao direito de aprender dos alunos.

A teoria, entretanto, não pode ser o único aspecto a ser trabalhado na educação jurídica, pois corre-se o risco de tratar o fenômeno como mera abstração. No contexto do ensino dogmático, nem mesmo os exemplos, muitas vezes, se relacionam diretamente à realidade. Esse distanciamento prejudica o entendimento da técnica jurídica e das possibilidades transformadoras do Direito.

A mudança nessa situação passa pela utilização de metodologias voltadas a permitir o contato entre a dogmática e a prática, seguindo a regulamentação aplicável à espécie, cabendo ao docente prevenir e remediar o distanciamento entre o raciocínio jurídico e a realidade à qual o Direito deve ser aplicado.

Uma das ferramentas didáticas voltadas diretamente a esse objetivo é o denominado método do caso, que, por sua vez, dirige-se a possibilitar, mesmo em uma sala de aula, que os alunos possam compreender a aplicação do Direito a uma situação realística. Não se trata, entretanto, de algo tradicional na educação jurídica brasileira.

Isso porque no Brasil o docente, comumente, acaba por se tornar um transmissor de conhecimentos abstratos ou, até mesmo, um mediador na aprendizagem de conceitos. Essa abordagem meramente expositiva produz o distanciamento entre teoria e realidade, além de prejudicar o contato entre professor e aluno.

Os métodos casuísticos, por sua vez, incentivam o debate de interpretações e ideias e viabilizam a aproximação dos próprios alunos entre si, bem como o intercâmbio de conhecimentos e questionamentos, permitindo a evolução conceitual, prática e crítica e o desenvolvimento da adaptabilidade a novas situações.

O método do caso, que difere conceitualmente do estudo de caso e da análise de julgados, tem origem no common law. Todavia, especialmente após a superveniência do Código de Processo Civil de 2015 e, consequentemente, do sistema de precedentes, é 
plenamente adaptável às necessidades do ensino do Direito no Brasil, mesmo sendo esse de tradição romanística.

Referido método, contudo, exige do professor uma preparação teórica sólida, o conhecimento amplo sobre a casuística estudada e uma preparação pedagógica específica. Isso porque sua grande vantagem, em relação às metodologias tradicionais utilizadas nos cursos de Direito, situa-se na aproximação que propicia entre os aspectos teóricos do Direito e sua aplicação prática.

O método do caso não é, portanto, uma ferramenta simples, especialmente em decorrência do fato de necessitar que do docente uma maior preparação e dedicação - uma melhor formação didático-pedagógica. Mas utilizada de forma adequada, pode gerar um grande ganho, durante o processo de ensinagem, no desenvolvimento das competências indispensáveis aos profissionais do Direito.

\section{REFERÊNCIAS}

ANDRÉ, Marli Eliza Dalmazo Afonso de. Estudo de caso em pesquisa e avaliação educacional: Brasília: Liber, 2008. (Série Pesquisa - v. 13)

AZEVEDO, Plauto Faraco de. Considerações teórico-práticas sobre a educação jurídica. Crítica Jurídica, n. 25, p. 223-231, jan.-dez. 2006.

CONANT, James Bryant. Dois modos de pensar: meus encontros com a ciência e a educação. São Paulo: Nacional, 1968.

FERRAZ JÚNIOR, Tércio Sampaio. Introdução ao estudo do Direito: técnica, decisão, dominação. 11. ed. São Paulo: Atlas, 2019.

MENEZES, Maria Arlinda de Assis. Do método do caso ao case: a trajetória de uma ferramenta pedagógica. Educação e pesquisa, v. 35, n. 1, p.129-143, abr. 2009

PLASTINA JÚNIOR, Márcio Gabriel; LEAL, Leonardo José Peixoto. A relevância do método do caso na atual conjuntura da educação jurídica brasileiro. Revista Expressão Católica, v. 7, n. 1; p. 14-19, jan.-jun., 2018.

RODRIGUES, Horácio Wanderlei. Planejando atividades de ensino-aprendizagem para cursos de Direito. In: RODRIGUES, Horácio Wanderlei; ARRUDA JÚNIOR, Edmundo Lima de. (Org.). Educação jurídica. 2. ed. Florianópolis: FUNJAB, 2012, p. 361-384. (Pensando o Direito no Século XXI - v.2) 
RODRIGUES, Horácio Wanderlei; BORGES, Marcus Vinícius Motter. O método do caso na educação jurídica. Quaestio Iuris, v. 9, n. 3, p. 1363-1388, 2016.

SAID FILHO, Fernando Fortes; ACIOLY FILHO, Evaldo Ferreira. Introdução do estudo de caso como ferramenta necessária ao adequado ensino da mediação no Brasil. In: ROCHA, Maria Vital da; BARROSO, Felipe dos Reis Barroso. (Org.). Educação jurídica e didática no ensino do Direito: estudos em homenagem Professora Cecilia Caballero Lois. Florianópolis: Habitus, 2020, p. 117-134.

SANTI, Eurico Marcos Diniz de. O desafio da interdisciplinaridade: do fato à norma, da realidade ao conceito jurídico. In: GHIRARDI, José Garcez; VANZELLA, Rafael Domingos Faiardo. (Org.). Ensino jurídico participativo: construção de programas, experiências didáticas. São Paulo: Saraiva, 2009, p. 139-152 (Série metodologia e ensino - Direito desenvolvimento justiça)

SUNDFELD, Carlos Ari; PALMA, Juliana Bonacorsi de. Ensinando Direito pelo concreto. In: FEFERBAUM, Marina; GHIRARDI, José Garcez. (Org.). Ensino do Direito para um mundo em transformação. São Paulo: FGV, 2012, p. 168-200.

TASSIGNY, Mônica Mota; FREIRE, Cylviane Maria Cavalcante de Brito Pinheiro; NOTTINGHAM, Andréa de Boni; KARAM, Andréa Maria Sobreira. A aplicabilidade do método do estudo de caso em pesquisas jurídicas. Revista Acadêmica da Faculdade de Direito do Recife, v. 88, n. 1, p. 39-57, jan.-jun., 2016. 